\title{
High incidence of penicillin resistance amongst clinical isolates of Streptococcus pneumoniae in northern Palestine
}

\author{
K. ADWAN, N. ABU-HASAN, A. HAMDAN and S. AL-KHALILI \\ Department of Biological Sciences, An-Najah National University, Nablus, Palestine
}

\begin{abstract}
One hundred and thirteen consecutive isolates of Streptococcus pneumoniae were collected in Nablus, Palestine between March and Aug. 1997 from children with acute lower respiratory tract infections. Resistance rates were: penicillin $88 \%$, cefuroxime $85 \%$, erythromycin $63 \%$, tetracycline $45 \%$, chloramphenicol $27 \%$ and ofloxacin $2 \%$. Resistances to erythromycin and cefuroxime were significantly associated with penicillin resistance. Ofloxacin may be useful against pneumococci resistant to traditional antimicrobial agents. Factors associated with penicillin resistance included hospitalisation and previous use of $\beta$-lactam antibiotics.
\end{abstract}

\section{Introduction}

Penicillin has long been the drug of choice for the treatment of pneumococcal infections, but there has been a world-wide increase in reports of penicillin resistance in pneumococci since the 1960 s. In many cases, penicillin resistance is associated with multiple resistances to other antibiotics [1,2] and this situation is causing increased concern. The present study aimed to obtain a snapshot of pneumococcal resistance in northern Palestine, a part of the world not previously surveyed for this type of resistance.

\section{Materials and methods}

Subjects and study design

This study was performed at An-Najah National University, Nablus, Palestine between March and Aug. 1997. Study participants were children $<8$ years of age from a private paediatric out-patient population and the paediatric in-patient ward at the Al-Watani Hospital, a referral centre for children in northern Palestine. The children were evaluated by one of two study physicians and selected if they had the symptoms of acute lower respiratory tract infection: i.e., cough, fever, tachypnoea (respiratory rate $>50 / \mathrm{min}$ ), leucocytosis, chest retraction or pulmonary infiltrates on chest X-ray [3,4]. Information regarding underlying

Received 10 Nov. 1998; revised version accepted 30 April 1999.

Corresponding author: Dr K. Adwan (e-mail: adwan@najah. edu). illnesses, hospitalisation and previous antibiotic use (including over-the-counter drugs) was recorded on a standardised questionnaire completed with the help of the study physicians. Previous use of antibiotic included all antibiotics received within 1 month before the culture date.

\section{Sample collection and processing}

Nasal or oropharyngeal samples were obtained. A nasal specimen was obtained from a depth of $1 \mathrm{~cm}$ in the nostril with a cotton-tipped swab. Oropharyngeal swab specimens were obtained from the posterior wall of the oropharynx. Pneumococci were identified by their $\alpha$ haemolysis on sheep blood agar (Oxoid Blood Agar Base No. 2), colony morphology and susceptibility to an optochin disk (Oxoid). Their identity was further confirmed by the coagglutination test (Phadebact Pneumococcus Test; Pharmacia, Uppsala, Sweden).

\section{Antimicrobial susceptibility testing}

Isolates were screened for penicillin resistance with $1-\mu \mathrm{g}$ oxacillin disks (Oxoid) by the Kirby-Bauer method. Isolates giving inhibition zones of $\geqslant 20 \mathrm{~mm}$ were considered penicillin-susceptible, whereas those with smaller zones were considered penicillin-resistant [5]. These latter isolates giving a zone $<20 \mathrm{~mm}$ were confirmed as penicillin-resistant by MIC tests on Mueller-Hinton Agar (Oxoid) supplemented with sheep blood 5\% [6]. The penicillin MICs (mg/L) used to define susceptible, intermediately resistant and resistant isolates were $<0.1,0.1-1.0$ and $>1.0$, respectively, as proposed by the National Committee for Clinical 
Laboratory Standards [7]. Throughout the rest of this report, the term 'penicillin-resistant' is used to refer collectively to both intermediately resistant and fully resistant isolates. Susceptibility to other antibiotics was tested by the Kirby-Bauer disk diffusion method on Mueller-Hinton agar supplemented with sheep blood $5 \%$ and incubated in an atmosphere containing $\mathrm{CO}_{2}$ $5 \%$. Disks were from Oxoid and the zones of inhibition were interpreted according to the recommendations of the National Committee for Clinical Laboratory Standards [8]. S. pneumoniae ATCC 6305 was used as the control strain.

\section{Statistical analyses}

Statistical analysis was performed with the programme Statistical Package for Social Sciences (SPSS, Chicago, IL, USA). For risk factor analysis, relative risks for infection with penicillin-resistant pneumococci versus susceptible strains were calculated, along with their $95 \%$ confidence intervals by the $\chi^{2}$ test. A p value $<0.05$ was considered statistically significant. Risk factors studied included the patients' gender, underlying disease, hospitalisation and previous antibiotic use.

\section{Results}

Altogether, 510 children with symptoms of acute lower respiratory infection were enrolled in the study. Of these, $111(21.8 \%)$ were admitted to Al-Watani Hospital for treatment. The median age was 36 months (range 10 days to 144 months); a definite infiltrate on the X-ray was seen in $22.5 \%$ of the children, as judged by radiologists. Diagnosis was based on the clinical signs or symptoms in the remaining children.

A total of 113 isolates of $S$. pneumoniae was identified (Table 1). Resistance to penicillin was seen in $88 \%$ of these, resistance to cefuroxime in $85 \%$, to erythromycin in $63 \%$, to tetracycline in $45 \%$, to chloramphenicol in $27 \%$ and to ofloxacin in $2 \%$. High-level penicillin resistance (MIC $>1 \mathrm{mg} / \mathrm{L}$ ) was seen in $77 \%$ of the penicillin-resistant isolates.

Table 1. Resistance to penicillin and its association with resistance to other antibiotics in 113 clinical isolates of S. pneumoniae

\begin{tabular}{|c|c|c|c|c|c|c|}
\hline \multirow{2}{*}{$\begin{array}{l}\text { Penicillin } \\
\text { susceptibility } \\
\text { (number of isolates) }\end{array}$} & \multicolumn{6}{|c|}{ Number of isolates resistant to } \\
\hline & Ery & Chl & $\mathrm{Cxm}$ & Tet & Off & $\begin{array}{c}\text { Multiple } \\
\text { antibiotics* }\end{array}$ \\
\hline Susceptible (14) & 5 & 1 & 7 & 4 & 0 & 2 \\
\hline Resistant (99) & $66^{\dagger}$ & 29 & $89^{\dagger}$ & 47 & 2 & $48^{\dagger}$ \\
\hline Total (113) & 71 & 30 & 96 & 51 & 2 & 50 \\
\hline
\end{tabular}

Ery, erythromycin; Chl, chloramphenicol; $\mathrm{Cxm}$, cefuroxime; Tet, tetracycline; Ofl, ofloxacin.

* Isolates resistant to at least two of erythromycin, chloramphenicol, tetracycline and ofloxacin.

${ }^{\dagger}$ Statistically significant differences compared with penicillin-susceptible pneumococci $\left(\mathrm{p}<0.05\right.$ in $\chi^{2}$ test).
The rates of resistance to erythromycin, chloramphenicol, cefuroxime and tetracycline were higher among penicillin-resistant than penicillin-susceptible isolates (Table 1) and these differences were statistically significant $(p<0.05)$ for erythromycin and cefuroxime. Likewise, multiresistance occurred significantly more frequently $(\mathrm{p}<0.05)$ in penicillin-resistant than penicillin-susceptible isolates, and $49 \%$ of the penicillinresistant isolates were resistant to at least two of erythromycin, chloramphenicol, tetracycline and ofloxacin.

Table 2 shows the predominant antibiotic resistance patterns encountered. Only five isolates (4\%) were susceptible to all the antibiotics; the remaining 108 showed 21 different patterns of resistance.

Significant risk factors associated with penicillinresistant pneumococci are listed in Table 3. Antibiotic use within the previous month was significantly associated with penicillin resistance: specifically, prior $\beta$-lactam use was a risk factor for penicillin resistance, whereas prior trimethoprim-sulphamethoxazole and erythromycin treatment were not risk factors. Of 36 children who had received antibiotics, $5(14 \%)$ gave a history of use of over-the-counter $\beta$-lactams. Penicillin resistance was also associated with hospitalisation: among 31 hospitalised children there were 30 (97\%) carriers of penicillin-resistant pneumococci. Ten of these carriers (33\%) acquired the organism in hospital, the remaining 20 had the organism before hospitalisation and remained persistent carriers. Underlying disease and the patient's gender had no apparent association with penicillin-resistant pneumococci.

\section{Discussion}

Antibiotic-resistant pneumococci - especially those with penicillin resistance - are increasingly isolated, and are a serious problem in many areas. Many strains are multiresistant: South Africa, New Mexico (USA)

Table 2. Resistance patterns among 113 pneumococcal isolates

\begin{tabular}{lc}
\hline Resistance pattern & Number of isolates (\%) \\
\hline Susceptible* & $5(4)$ \\
Pen, Tet, Ery, Cxm & $23(20)$ \\
Pen, Ery, Cxm & $20(18)$ \\
Pen, Chl, Ery, Cxm & $5(4)$ \\
Pen, Chl, Tet, Cxm & $4(4)$ \\
Pen, Chl, Tet, Ery, Cxm & $14(12)$ \\
Pen, Chl, Tet, Ery, Cxm, Ofl & $2(2)$ \\
Pen, Cxm & $17(15)$ \\
Pen & $6(5)$ \\
Cxm & $3(2)$ \\
Tet, Ery, Chl, Cxm & $1(1)$ \\
Tet, Ery, Cxm & $1(1)$ \\
Other 10 patterns & $12(11)$ \\
Total & $113(100)$ \\
\hline
\end{tabular}

Abbreviations as in Table 1.

${ }^{*}$ Susceptible to all antibiotics tested. 
Table 3. Risk factors associated with penicillin-resistant pneumococci

\begin{tabular}{|c|c|c|c|c|}
\hline \multirow[b]{2}{*}{ Factor } & \multicolumn{2}{|c|}{ Penicillin susceptibility } & \multirow[b]{2}{*}{$\mathrm{p}$ value } & \multirow[b]{2}{*}{ Odds ratio $(\mathrm{CI})$} \\
\hline & $\begin{array}{l}\text { Resistant } \\
(\mathrm{n}=99)\end{array}$ & $\begin{array}{l}\text { Susceptible } \\
(\mathrm{n}=14)\end{array}$ & & \\
\hline Age (months) (SD) & $29(31)$ & $30.2(18)$ & & \\
\hline $\begin{array}{l}\text { Gender } \\
\text { Male } \\
\text { Female }\end{array}$ & $\begin{array}{l}60 \\
39\end{array}$ & $\begin{array}{r}10 \\
4\end{array}$ & NS & $0.62(0.18-2.10)$ \\
\hline $\begin{array}{l}\text { Hospitalisation } \\
\text { Yes } \\
\text { No }\end{array}$ & $\begin{array}{l}30 \\
69\end{array}$ & $\begin{array}{r}1 \\
13\end{array}$ & 0.042 & $5.65(0.71-45.18)$ \\
\hline $\begin{array}{l}\text { Underlying disease } \\
\text { Yes } \\
\text { No }\end{array}$ & $\begin{array}{l}12 \\
87\end{array}$ & $\begin{array}{r}1 \\
13\end{array}$ & NS & $1.79(0.22-14.96)$ \\
\hline $\begin{array}{l}\text { Previous antibiotic use* } \\
\beta \text {-Lactam } \\
\text { Trimethoprim/sulphamethoxazole } \\
\text { Erythromycin } \\
\text { None }\end{array}$ & $\begin{array}{r}33 \\
1 \\
1 \\
64\end{array}$ & $\begin{array}{r}1 \\
0 \\
0 \\
13\end{array}$ & $\begin{array}{l}0.023 \\
\text { NS } \\
\text { NS }\end{array}$ & $\begin{array}{l}7.95(0.84-53.48) \\
0.99(0.96-1.02) \\
0.99(0.96-1.02)\end{array}$ \\
\hline
\end{tabular}

NS, not statistically significant $(p>0.05)$.

* Antibiotics received within 1 month before culture date.

[9], Hungary [10] and Spain [11] all have reported penicillin resistance rates nearing $50 \%$, and even higher prevalence rates have been reported in the Far East [12]. Data from the present study indicate an extremely high rate $(88 \%)$ for penicillin-resistant pneumococci in Palestine. This high rate is probably due, in part, to the selective pressure resulting from uncontrolled, inappropriate and frequent administration of penicillin and its derivatives. This is promoted by the lack of an antibiotic policy and the availability of antibiotics sold over-the-counter. The high rate of resistance has major therapeutic implications, insofar as penicillin resistance is associated with multiresistance $[10,13,14]$. Nearly half $(49 \%)$ of the penicillin-resistant isolates (MIC $>1 \mathrm{mg} / \mathrm{L}$ ) were also resistant to at least two or more of erythromycin, chloramphenicol, tetracycline and ofloxacin (Table 2). Nevertheless, resistance to ofloxacin was not related to resistance to other agents. Therefore, ofloxacin may provide an alternative therapy for use in patient populations likely to be colonised with multiresistant pneumococci [15].

Analysis showed that hospitalisation was associated with carriage of penicillin-resistant pneumococci. This finding is consistent with the close inter-personal contact and frequent antimicrobial drug usage that co-exist in hospitals $[16,17]$, favouring transmission and persistence of resistant bacteria. As found in previous reports $[16,18]$, children who had received $\beta$ lactam antibiotics in the present study were more likely than other children to carry penicillin-resistant pneumococci. Moreover, antimicrobial agents may eradicate sensitive organisms from the oropharynx and facilitate the establishment of a resistant strain.

In conclusion, the high frequency of penicillin resistance among $S$. pneumoniae has clearly emerged as a serious problem in Palestine. It is necessary to carry out continuous surveillance of this problem to generate accurate local data and identify alternative therapies.

The authors thank the staff of the Al-Watani Hospital for their assistance in obtaining the bacterial isolates. This study was partially supported by a grant from the Third World Academy of Sciences (TWAS).

\section{References}

1. Johnson AP. Antibiotic resistance among clinically important gram-positive bacteria in the UK. $J$ Hosp Infect 1998; 40: $17-26$.

2. Kanavaki S, Karabela S, Marinis E, Legakis NJ. Antibiotic resistance of clinical isolates of Streptococcus pneumoniae in Greece. J Clin Microbiol 1994; 32: 3056-3058.

3. Musher DM. Pneumococcal pneumonia including diagnosis and therapy of infection caused by penicillin-resistant strains. Infect Dis Clin North Am 1991; 5: 509-521.

4. Chong CY, Lim WH, Heng JT, Chay OM. The changing trend in the pattern of infective etiologies in childhood acute lower respiratory tract infection. Acta Paediatr Jpn 1997; 39: 317-321.

5. Marshall KJ, Musher DM, Watson D, Mason EO. Testing of Streptococcus pneumoniae for resistance to penicillin. $J$ Clin Microbiol 1993; 31: 1246-1250.

6. Lauer BA, Reller LB. Serotypes and penicillin susceptibility of pneumococci isolated from blood. J Clin Microbiol 1980; 11: $242-244$.

7. National Committee for Clinical Laboratory Standards. Performance standards for antimicrobial disc susceptibility tests: Document M2-A5. Villanova, PA, NCCLS. 1993.

8. National Committee for Clinical Laboratory Standards. Performance standards for antimicrobial susceptibility tests. Document M7-A. Villanova, PA, NCCLS. 1985.

9. Klugman KP. Pneumococcal resistance to antibiotics. Clin Microbiol Rev 1990; 3: 171-196.

10. Marton A, Gulyas M, Munoz R, Tomasz A. Extremely high incidence of antibiotic resistance in clinical isolates of Streptococcus pneumoniae in Hungary. J Infect Dis 1991; 163: $542-548$.

11. García-Leoni ME, Cercenado E, Rodeňo P, Bernaldo de Quirŏs JCL, Martínez-Hernández D, Bouza E. Susceptibility of Streptococcus pneumoniae to penicillin: a prospective microbiological and clinical study. Clin Infect Dis 1992; 14: 427-435. 
12. Kam KM, Luey KY, Fung SM, Yiu PP, Harden TJ, Cheung MM. Emergence of multiple-antibiotic-resistant Streptococcus pneumoniae in Hong Kong. Antimicrob Agents Chemother 1995; 39: $2667-2670$.

13. Doern GV, Brueggmann A, Holley HP, Rauch AM. Antimicrobial resistance of Streptococcus pneumoniae recovered from outpatients in the United States during the winter months of 1994 to 1995: results of a 30-center national surveillance study. Antimicrob Agents Chemother 1996; 40: 1208-1213.

14. Liňares $\mathrm{J}$, Pallares $\mathrm{R}$, Alonso $\mathrm{T}$ et al. Trends in antimicrobial resistance of clinical isolates of Streptococcus pneumoniae in Bellvitge hospital, Barcelona, Spain (1979-1990) Clin Infect Dis 1992; 15: 99-105.

15. Plouffe JF, Herbert MT, File TM et al. Ofloxacin versus standard therapy in treatment of community-acquired pneumo- nia requiring hospitalization. Antimicrob Agents Chemother 1996; 40: 1175-1179.

16. Arason VA, Kristinsson KG, Sigurdsson JA, Stefánsdóttir G Mölstad S, Gudmundsson S. Do antimicrobials increase the carriage rate of penicillin resistant pneumococci in children? Cross sectional prevalence study BMJ 1996; 313: $387-391$.

17. Huang F, Chiu N, Liu S. Penicillin-resistant pneumococcal infections in children. $J$ Formos Med Assoc 1997; 96: 414-418.

18. Dagan R, Melamed R, Muallem M, Piglansky L, Yagupsky P Nasopharyngeal colonization in Southern Israel with antibioticresistant pneumococci during the first 2 years of life: relation to serotypes likely to be included in pneumococcal conjugate vaccine. $J$ Infect Dis 1996; 174: 1352-1355. 